DOI 10.37882/2223-2974.2020.09.21

\title{
ОСОБЕННОСТИ УГОЛОВНО-ПРАВОВОЙ ХАРАКТЕРИСТИКИ ИЗГОТОВЛЕНИЯ И ОБОРОТА МАТЕРИАЛОВ ИЛИ ПРЕДМЕТОВ С ПОРНОГРАФИЧЕСКИМИ ИЗОБРАЖЕНИЯМИ НЕСОВЕРШЕННОЛЕТНИХ
}

\section{FEATURES OF CRIMINAL-LEGAL CHARACTERISTICS OF MANUFACTURING AND TRAFFICKING OF MATERIALS OR OBJECTS WITH PORNOGRAPHIC IMAGES OF MINORS}

\section{Pryanikova}

Summary: The article provides a detailed analysis of scientific research on the definition of the concept of "pornography», the influence of pornography on public morals and determining the nature of public danger caused by the circulation of pornographic objects. The article highlights the criteria for classifying products as having a pornographic character, as well as the distinction between pornography and eroticism. Special attention is paid to the detailed development of criminological problems of countering sexual crime. Analysis of scientific literature showed that the substantive aspect is still unexplored, there are a number of issues, in particular: specific features of criminal law characteristics of the production and turnover of materials or subjects with pornographic images of minors.

International and domestic legal acts regulating the basic principles of cooperation and interaction of States to prevent, detect and counteract the trafficking of pornographic items are analyzed.

Keywords: pornography, products of a pornographic nature, turnover of pornographic items, public morality, minors, child pornography, corruption of minors.
Пряникова Мария Анатольевна

Аспирант, Московский городской педагогический университет Pryanikovamaria@mail.ru

Аннотация: В статье проведен детальный анализ научных исследований относительно определения понятия «порнография», влияния порнографии на общественную мораль и определения характера общественной опасности, наносимого в результате обращения порнографических предметов. Освещены критерии отнесения продукции к имеющей порнографический характер, а также разграничение порнографии от эротики.

Особое внимание уделено детальной разработке криминологических проблем противодействия половой преступности. Анализ научной литературы показал, что в материально-правовом аспекте до сих пор неисследованной есть ряд вопросов, в частности: особенности уголовно-правовой характеристики изготовления и оборота материалов или предметов с порнографическими изображениями несовершеннолетних.

Проанализированы международные и отечественные нормативно-правовые акты, регламентирующие основные принципы сотрудничества и взаимодействия государств по предотвращению, выявлению и противодействию обороту порнографических предметов.

Ключевые слова: порнография, продукция порнографического характера, оборот порнографических предметов, общественная мораль, несовершеннолетние, детская порнография, развращение малолетних.
Ю ристы по-разному соотносят половую свободу и половую неприкосновенность. Одни считают их самостоятельными категориями, что как объекты уголовно-правовой охраны не пересекаются. Следовательно, несовершеннолетие лицо имеет половую неприкосновенность, но не имеет половой свободы. В то же время взрослые, приобретая половую свободу, теряют половую неприкосновенность. Вторые считают, что половую свободу и половую неприкосновенность родственными категориями, частично или полностью пересекаются, и настойчиво утверждают, что несовершеннолетние лица также, наряду с взрослыми женщинами и мужчинами, имеют половую свободу. Третьи же, наоборот, убеждены, что несовершеннолетние, если они даже не достигли половой зрелости, приобретают половую свободу в полном объеме с момента достижения ими возраста, что дает возможность осознавать значение и роль половых отношений. Что же касается малолетних, то из-за их психофизического развития они не имеют возможности осознавать роль и значение половых сношений, а потому, соответственно, не могут иметь половой свободы.

Существуют даже рассуждения, что половая неприкосновенность распространяется на лица мужского и женского пола в любом возрасте, а не только на малолетних и несовершеннолетних. Право на половую неприкосновенность и половую свободу предоставляется всем независимо от пола и возраста, степени морального достоинства и добродетели. В то же время вопрос по- 
нимания ключевого для нашего исследование понятия станет предметом рассмотрения в следующих частях статьи.

Половая свобода является неотъемлемой составляющей комплекса природных прав и свобод человека. Специальная литература также охватывает содержание понятия «половая неприкосновенность», определяет структуру этого объекта уголовно-правовой охраны и тому подобное. Так, по мнению В.В. Кулгина и М.П. Полянской, половая неприкосновенность имеет многоуровневую общественно-правовую регуляцию. Можно выделить общественно-ценностный, гражданско-правовой, специально-медицинский, информационный и физический уровни [8]. Отдельно, социально-ценностный уровень отражает моральные ценности общества, который одобряет своевременное, постепенное вхождение лица в полноценные половые сношения.

Общественная мораль осуждает любое грубое половое обращения с детьми и подростками, впрочем поощряет и направляет в познавательное русло религиозные, семейные или школьные беседы (программы) по половому воспитанию. Из приведенного очевидно, что половая неприкосновенность, прежде всего, является предпосылкой, которую должно обеспечить государство и общество для нормального физического и психического развития ребенка и подростка.

Федеральным законом от 8 декабря 2003 г. №162-Ф3 в Уголовный кодекс РФ был внесен ряд изменений, которые затронули и рассматриваемую проблему. В частности, гл. 25 УК РФ «Преступления против здоровья населения и общественной нравственности» была дополнена ст. 242.1, предусматривающей ответственность за изготовление и оборот материалов и предметов с порнографическими изображениями несовершеннолетних. Ранее данное преступление не выделялось в качестве самостоятельного состава. Ответственность наступала по ст. 242 УК РФ.

В рамках современной педиатрической науки нормальное физическое, психическое, умственное и духовное развитие человека обусловлен огромным разнообразием природных (географических, климатических, и др.), социальных (экономических, правовых, информационных и др.), индивидуальных (половых, возрастных, образовательных и др.) факторов. Будучи во взаимодействии и взаимозависимости друг от друга, комбинируя между собой, они берут непосредственное участие в формировании физического, психического и духовного развития ребенка с рождения и взрослого человека на протяжении всей жизни. Поэтому половую неприкосновенность, по мнению ученых, следует связывать исключительно с нормальным половым физическим и психическим развитием несовершеннолетнего.
Незаконное влияние на информативный уровень половой неприкосновенности несовершеннолетних является крайне опасным для общества и нуждается в уголовно-правовой охране. Основное социальное направление объекта уголовно-правовой охраны заключается в невозможности информационного влияния на половую неприкосновенность несовершеннолетних. Содержание непосредственного объекта предопределяет механизм причинения ему преступного ущерба путем развратных действий физического и интеллектуального характера.

Под физическими развратными действиями понимают обнажение половых органов виновного или потерпевшего лица, непристойные прикосновения к половым органам, которые вызывают половые возбуждения, обучение половым извращениям, имитация полового акта, склонение или принуждение потерпевших к совершению определенных сексуальных действий между собой, совершение полового сношения, акта в присутствии потерпевшего лица и тому подобное [2].

Под интеллектуальными развратными действиями ознакомление потерпевшего с порнографическими изображениями, видеофильмами, циничные разговоры с ней на сексуальные темы и тому подобное. Впрочем, интеллектуальными такие действия назвать сложно, поэтому кажется, что более выразительным было бы их определение как «психическое насилие» [14].

Очевидно, что преступления против половой свободы и неприкосновенности лиц, не достигшие шестнадцатилетнего возраста, составляют повышенную общественную опасность, так как их последствиями являются глубокие психологические травмы, которые негативно сказываются на дальнейшей жизни несовершеннолетнего и даже могут стать криминогенными факторами для общества [6].

История человечества охватывает множество различных запретов, касающихся половых сношения с детьми. Некоторые из них были обусловлены сугубо рациональным взглядом на репродуктивные функции рода, некоторые - национальным менталитетом и культурными особенностями, религиозными предписаниями.

Исследование древних правовых и религиозных памятников свидетельствует, что человечество, прежде всего, осознало недопустимость насильственных половых актов в отношении несовершеннолетних и малолетних, а также добровольных половых контактов инцестного характера. Что же касается ненасильственных половых сношений с лицами, не достигшими половой зрелости, то в некоторых случаях они могли расцениваться как проявления блуда или считаться прелюбодеянием, если один из участников состоял в брачных 
отношениях. Жрецы, священники, а впоследствии и законодатель отводили урегулированию сексуальной жизни народа не последнее место, понимая важность этого вопрос для стабильности и развития общества. Истории сексуальных запретов и предписаний посвятили свои исследования специалисты в области социологии, психологии, психиатрии, уголовного права, криминологии [7].

Первые международные акты о прекращении оборота порнографии были приняты в начале XX века и ратифицированы многими государствами мира. К таким актам следует отнести соглашение о прекращении обращения порнографических изданий (1910 г.), Международную конвенцию о пресечении обращения порнографических изданий и торговли ими (1923 г.), Протокол об изменении Соглашения относительно пресечения обращения порнографических изданий (1949 г.), Конвенцию о правах ребенка (1989 г.), Европейскую конвенцию о трансграничном телевидении (1998 г.), Конвенцию о киберпреступности (2003 г.).

Анализируя вышеуказанные международные договоры, целесообразно признать, что они регулируют основные вопросы международного сотрудничества по борьбе с оборотом порнографических предметов, однако не дают конкретные определения основных понятий и категорий, таких как «порнография», «порнографические предметы», «продукция порнографического характера», «оборот порнографических предметов», критерии отнесения продукции к такой, что имеет порнографический характер, разграничение ее от эротики и продукции сексуального характера.

В то же время ст. 1 Международной конвенции о пресечении обращения порнографических изданий и торговли ими (1923 г.) предусматривается ответственность за оборот порнографических предметов и определяется, какие именно материальные объекты с порнографическим содержанием можно отнести к продукции порнографического характера.

Следует отметить, что среди ученых не существует единой точки зрения относительно понятия «порнография». Например, А.В. Польшиков, исследовав работы современных ученых, пришел к выводу, что порнография - это произведения, изображения и другие предметы сексуального характера, предназначены для возбуждения патологической половой страсти [11].

В то же время А.С. Валентонис в диссертации отмечает необходимым минимизировать количество оценочных понятий в дефиниции «порнография» и понимать под последней натуралистическое изображение или описание половых органов персонажей (людей, животных), в частности, и в момент совершения ими или в отношении них половых действий [3].
Р.С. Джинджолия дает определения понятия порнографии как демонстративного визуального или звукового изображения полового акта, а также описание физиологии половых органов персонажей (людей, животных), в частности, в момент совершения ими или в отношении них действий сексуального характера [7].

Понятие «порнография» рассматривалось на диссертационном уровне О. В. Бесчастновой, которая предлагает законодательно закрепить понятие порнографии как вульгарно-натуралистического изображения или описания физиологических элементов половых актов, половых органов или непристойных форм сексуального поведения с целью возбуждение половых инстинктов, не имеющее научного или просветительского характера и художественной ценности [5].

А вот М.В. Гусарова отмечает, что порнография - это детальная демонстрация половых органов или полового акта, умышленно созданная с целью проявления сильного полового возбуждения, не имеющего при этом культурной, научной и исторической ценности и является по своей сути оскорбительной для общественной морали [4].

К продукции порнографического характера относятся любые материальные объекты, предметы, печатная, аудио-, видеопродукция, в том числе реклама, сообщения и материалы, продукция средств массовой информации, электронных средств массовой информации, предназначенные для удовлетворения сексуальных потребностей человека [14].

С.В. Тасаков относит к такой продукции «порнографические тексты, фотоизделия, изображения, изделия, орудия, сувениры и бытовые предметы, кино - видеопродукция, звукозаписи, комбинированные изделия и сборки материалов» [12].

Как уже было отмечено ст. 1 Международной конвенции о прекращении обращения порнографических изданий и торговли ими (1923 г.) определяется, какие именно материальные объекты с порнографическим содержанием можно отнести к продукции порнографического характера, а именно «изготовление или хранение, сочинений, рисунков, гравюр, картин, печатных изданий, изображений, афиш, эмблем, фотографий, кинематографических фильмов или других порнографических предметов, с целью их продажи или распространения, или же публичного их выставления; ввоз, провоз, вывоз лично или через другое лицо в вышеуказанных целях перечисленных предметов или пуск их тем или другим путем в обращение; торговлю ими даже не публичная, совершение с ними всяких операций какого бы то ни было вида, распространение их, публичное их выставление или же сдача их, как профессии, в прокат; анонсирование 
или объявление любым путем, в целях поощрения обращения или торговли, подлежащих прекращению, что любое лицо занимается одним из вышеперечисленных наказуемых действий, анонсирование или оглашение, как и через кого вышеуказанные предметы могут быть получены, либо непосредственно, либо через чье-либо посредничество» [10].

Подытоживая изложенное, под порнографией мы предлагаем понимать грубое, непристойное, грубо натуралистическое изображение сексуальных действий (в некоторых случаях противоестественного полового акта), детальное изображение половых органов и манипуляций с ними с использованием крупного плана, что имеет своей целью возбуждения первобытных сексуальных инстинктов и побуждения к половому акту, выраженная в любом материальном виде или содержащейся на любых материальных носителях информации и не имеет в отличие от эротики научного или художественного значения.

Детская порнография, являющаяся особо тяжкой формой сексуальной эксплуатации детей, принимает в последние годы все более широкие масштабы и распространяется посредством использования новых технологий и сети Интернет. Она представляет собой грубое нарушение основополагающего права ребенка на гармоничное воспитание и развитие.

Ларина О.К. указывает, что «несформировавшееся сознание молодежи склонно воспринимать порнографию как возможную модель сексуального поведения (вступление в сексуальные отношения с применением насилия, против воли партнера, без какой-либо личной привязанности, беспорядочные связи, извращенные формы сексуального поведения). Но в данном случае, кроме самоутверждения, демонстрации своего превосходства, власти над другим человеком, подростки стремятся удовлетворить в жестокой форме и основной природный инстинкт - получить сексуальное удовлетворение» [9].

Относительно преступлений, в которых половая неприкосновенность может выступать дополнительным объектом, то в УК различных государств Европы преступные деяния, связанные с порнографией и проституцией, относятся к различным группам: к преступным деяниям или против воли, или против нравственности или против половой свободы и половой неприкосновенности и тому подобное. Но в законодательстве большинства европейских государств уже учтены требования указанных актов международного и общеевропейского права.

В законодательстве США в главе 110 «Сексуальная эксплуатация и прочее злоупотребление детьми» (§§ 2251-2260) содержатся не только уголовно-правовые нормы, описывающие конкретные составы преступлений, но и общие уголовно-правовые нормы (уголовная конфискация, принудительная реституция) и гражданско-правовые нормы (гражданская конфискация и гражданско-правовые средства судебной защиты личных повреждений) [16]. Следовательно, уголовно-правовые положения этой главы, прежде всего, направлены на противодействие сексуальному использованию детей и детской порнографии. Главным понятием, с которым связана ответственность за сексуальную эксплуатацию и другое злоупотребление детьми, является «сексуально выраженная поведение».

В Российской Федерации ситуация сильно отличается. Федеральный закон от 29 июня 2013 г. № 135-Ф3 «О внесении изменений в статью 5 Ф3 «О защите детей от информации, причиняющей вред их здоровью и развитию» и отдельные законодательные акты Российской Федерации в целях защиты детей от информации, пропагандирующей отрицание традиционных семейных ценностей» [1], говорит о несовершеннолетних как о едином целом сообществе. Любой несовершеннолетний в России не должен подвергаться пропаганде нетрадиционных сексуальных отношений. Исключений нет.

Изменить мировоззрение взрослого человека невозможно, поэтому необходимо начинать формировать мировоззрение маленького существа с раннего возраста. Необходимо проводить профилактические мероприятия по оказанию помощи детям и семьям с детьми, начиная уже тогда, когда малыш приходит в детский сад. Ведь семья для ребенка - это та среда, которая его формирует как личность, воспитывает в нем духовность, нравственные качества, гражданскую позицию.

Считаем справедливыми высказанные в литературе предложения выделить в определенной степени расширить уголовно-правовой запрет понуждение человека к участию в создании предметов порнографического характера. Диспозиция этой нормы должна запрещать использование другого человека в создании продукции порнографического характера, совершенное с использованием обмана, шантажа или угрозы уничтожения имущества, использованием уязвимого состояния человека. Насилие и угрозу применения насилия, использование состояния материальной или иной зависимости или служебного положения необходимо закрепить как квалифицирующие и особо квалифицирующие обстоятельства. Целесообразно также установить повышенную ответственность за совершение такого преступления в отношении ребенка и дифференцировать ее в зависимости от возраста - несовершеннолетнего или малолетнего. Ответственность за использование малолетнего или несовершеннолетнего в создании продукции порнографического характера, за этой статьей дол- 
жен наступать независимо от того, совершены ли такие действия с использованием обмана, шантажа или уязвимого состояния этого лица, или с применением или угрозой применения насилия, угрозой уничтожения имущества, с использованием служебного положения или материальной или иной зависимости, или без любого из указанных способов.

В настоящее время президентом Российской Федерации В.В. Путиным подписан Указ об объявлении 2018-
2027 годов Десятилетием детства в России. Его целью является совершенствование государственной политике в сфере защиты детства, учитывая результаты, достигнутые в ходе реализации Национальной стратегии действий в интересах детей 2012-2017 годов. Безусловно, главным фактором в российской государственной семейной политике является семья - неделимое целое, та субстанция, которая обезопасит ребенка от возможных ошибочных решений сейчас и негативных последствий этих решений в дальнейшем.

\section{ЛИТЕРАТУРА}

1. Бесчастнова 0.В. Изготовление и оборот материалов или предметов с порнографическими изображениями несовершеннолетних: уголовно-правовой аспект : дисс. ... канд. юрид. наук : 12.00.08 / Бесчастнова 0.В.; [Место защиты: Рост. юрид. ин-т МВД РФ]. Ростов-на-Дону, 2008. 210 с.

2. Борисов Т. Прейскурант на невинность // Российская газета. 2005. 22 июля.

3. Валентонис А.С. Криминологические и уголовноправовые аспекты противодействия обороту предметов или материалов с порнографическими изображениями несовершеннолетних: дисс. канд. юр. наук. URL: http://lawtheses.com/kriminologicheskiei-ugolovno-pravovye-aspekty-protivodeystviyaoborotupredmetov-ili-materialov-spornograficheskimi-izo\#ixzz2wrmfa2m8 (дата обращения: 22.03.2020).

4. Гусарова М.В. Незаконный оборот порнографических материалов или предметов: уголовно-правовые и криминологические аспекты : дисс. ... канд. юрид. наук : 12.00.08. Казань, 2010. 262 с.

5. Джинджолия Р.С. Уголовная ответственность за незаконное распространение порнографических материалов или предметов / науч. ред. А.А. Магамедов ; Московский гос. ун-т сервиса. Филиал в г. Сочи. Москва; Сочи: [б.и.], 2001. 50 с.

6. Исаев Н.А. Сравнительно-исторический аспект половых преступлений // История развития уголовного права и ее значение для современности: материалы V Международной научно-практической конференции, состоявшейся на юридическом факультете МГУ им. М.В. Ломоносова (26-27 мая 2005 г.). М.: ЛексЭст, 2006. С. 141-146.

7. Капитунов А.С. Насильственные половые преступления против несовершеннолетних: дисс. . . . канд. юрид. наук. Краснодар, 2006. 200 с.

8. Кулыгин В.В., Полянская М.П. Установление уголовной ответственности за изготовление и оборот материалов или предметов с порнографическими изображениями несовершеннолетних // Безопасность бизнеса. 2007. № 2. С.56.

9. Ларина 0.К. Указ. соч. с.115.

10. Международная конвенция о пресечении обращения порнографических изданий и торговли ими (Вместе с «Соглашением относительно пресечения обращения порнографических изданий») (Конвенция заключена в г. Женеве 12.09.1923) (Соглашение заключено в г. Париже 04.05.1910) (с изм. 0т 04.05.1949). URL: http://www.consultant.ru/cons/cgi/online.cgi?req=doc\&base $=I N T \& n=15101 \# 04039349193070254$.

11. Польшиков А.В. Уголовно-правовые и криминологические меры борьбы с изготовлением и оборотом материалов с порнографическими изображениями несовершеннолетних в сети «Интернет». дисс. канд. юр. наук. URL: http://www.dissercat.com/content/ugolovno-pravovye-i-kriminologicheskie-meryborbys-izgotovleniem-i-oborotom-materialov-spo\#ixzz2wriln525 (дата обращения: 22.03.2020).

12. Тасаков С.В. Нравственные основы уголовно-правовых норм, направленных на охрану личности, ее прав, свобод и законных интересов: автореф. дис. на соискание уч. степени д-ра юрид. наук. Екатеринбург, 2010. 40 с.

13. Федеральный закон «0 внесении изменений в статью 5 Федерального закона «0 защите детей от информации, причиняющей вред их здоровью и развитию». - URL: http://www.consultant.ru/document/cons_doc_LAW_148269 (дата обращения 25.03.2020).

14. Шерешевский А.М., Павлов Г.Н., Васильева А.В. Агрессия и порнография. - СПб: Паритет, 1998. С.8.

15. Шмыков Д.В. Противодействие обращению порнографических материалов или предметов: уголовно-правовой и криминологический анализ: дис.... канд. юрид. наук.- Нижний Новгород, 2011.

16. Federal Criminal Code and Rules. St. Paul, Minn., West Group, 2003. 1436 p.

(с Пряникова Мария Анатольевна (Pryanikovamaria@mail.ru). Журнал «Современная наука: актуальные проблемы теории и практики» 